\title{
A spectral-analysis tutorial with examples in FORTRAN
}

\author{
SAMUEL P. STURGIS \\ Liberty Mutual Research Center, Hopkinton, Massachusetts
}

\begin{abstract}
A procedure for performing spectral analysis using a digital computer is described. The relevant analysis parameters and their interaction are reviewed, and the underlying mathematical theory of the analysis is annotated with page references to a standard reference text. A computer program that implements the procedure is presented in a general form of FORTRAN. Examples of the spectra produced by a variety of input time histories are shown.
\end{abstract}

Spectral analysis is a data-analysis technique that allows examination of the frequency composition of data that vary with time. This technique is applicable to the analysis of time history data that are bounded, continuous, stationary (possess mean and variance that are independent of time), and ergodic (possess mean and autocorrelation values that are equivalent when calculated from different sample functions). Fortunately, many physical processes and processes that represent the continuous output of a human being performing a steady-state task meet these requirements.

This paper summarizes a method for digitally calculating spectral estimates using the "Cooley-Tukey" method of performing a fast Fourier transform (FFT) directly on digitized time-history data, as described by Bendat and Piersol (1971) and Otnes and Enochson (1978). Both of these works present highly detailed discussions of the theory and application of a wide range of frequency-analysis techniques and are highly recommended to those interested in understanding the intricacies of spectral analysis and in developing more generalized frequency-analysis capabilities. The descriptions of the procedures herein are intended to represent a functional synopsis of the procedures described by Bendat and Piersol (1971) and Otnes and Enochson (1978), but with most of the accompanying rationale and mathematical derivation omitted to facilitate implementation. In most cases, page references to the Bendat and Piersol text are included to permit the reader to review the underlying theory in detail.

The description of the spectral-analysis methodology assumes that the reader understands the concept of spectral analysis and its applications, is conversant in the FORTRAN programming language, has access to a digital computer that can be programmed in FORTRAN, has sufficient computer hardware and software to digitize and store or otherwise acquire analog data, and has

The author's mailing address is: Wang Laboratories, Inc., M/S 1489, One Industrial Avenue, Lowell, Massachusetts 01851. access to the reference text to permit as much in-depth review of the detailed analysis rationale as desired.

This analysis procedure produces spectral estimates that represent the amount of power in frequency bands between $0 \mathrm{~Hz}$ and a maximum frequency ( $\mathrm{fc}$ ), each frequency band having a finite and equal resolution bandwidth (Be), number of degrees of freedom ( $n$ ), and normalized standard error (Er). The frequency range, resolution bandwidth, degrees of freedom, and normalized standard error are functions of: the digitizing or intersample time interval (h); the number of samples included in the analysis (also known as the record length or frame length) $(\mathrm{N})$; the product of these two values, the time interval $(\mathrm{T})$ over which data is sampled; and, if the spectrum-averaging procedures described later are used, the number of contiguous frequency bands (b) and/or number of individual time segments $(q)$ averaged. These parameters are related by the following equations (p. 330): $h=1 /(2 \mathrm{fc}) ; \mathrm{T}=\mathrm{N} * \mathrm{~h}$; $\mathrm{N}=\mathrm{T} / \mathrm{h} ; \mathrm{Be}=\mathrm{b} / \mathrm{T} ; \mathrm{Er}=1 /(\mathrm{bq})$. Although relatively complex algorithms exist that permit computation of FFTs (and thus spectra) with a very wide range of record lengths (Singleton, 1969), the more concise procedure described here requires that $\mathrm{N}$ be equal to 2 raised to an integer power (e.g., $N=2 * * 10=1,024 ; N=2 * * 11=$ $2,048)$. The use of this procedure results in the value of $h$ (the intersample time interval) being the single most critical parameter under the experimenter's control, and its selection primarily depends upon the maximum frequency that the experimenter is interested in examining. A major issue in selecting $h$ and subsequently digitizing analog data is ensuring that aliasing (confusion between the data of interest and extraneous higher frequency components) does not occur. A useful technique for avoiding aliasing, and which is used in some "hardwired" spectrum analyzers (GenRad, 1978), involves selecting $h=1 /(2.56 \mathrm{fc})$ [rather than $1 /(2 \mathrm{fc})$ ], low-pass filtering the input data with a sharp cutoff filter at $\mathrm{fc}$, and discarding the highest $(0.56 / 2.56$, or $21.875 \%)$ of the spectral estimates (which may still contain aliased components). This procedure has the added benefit of 
producing a round number of spectral estimates and a numerically reasonable $\mathrm{Be}$. The use of this procedure produces $\mathrm{Ng}$ spectral estimates: $\mathrm{Ng}=\mathrm{N} / 2 * 0.78125$.

For example, to examine the frequency range of $0-10 \mathrm{~Hz}$ with $\mathrm{N}=1,024$, set: $\mathrm{h}=1 / 25.6=39.0625$ milli$\sec ; \mathrm{T}=\mathrm{N} * \mathrm{~h}=40 \mathrm{sec} ; \mathrm{Be}=1 / \mathrm{T}=0.025 \mathrm{~Hz} ; \mathrm{Ng}=\mathrm{N} / 2 *$ $0.78125=400 ; \mathrm{fc}=\mathrm{Ng} * \mathrm{Be}=10 \mathrm{~Hz}$.

In cases in which the number of data to be analyzed is limited and is less than a convenient power of 2 , it is possible to add zeros to the end of the input record to create the appropriate number of data points. This procedure (which would be performed after the D.C. offset removal and before the windowing described later), changes $\mathrm{Be}$ from $\mathrm{Be}=1 /(\mathrm{N} * \mathrm{~h})$ to $\mathrm{Be}=1((\mathrm{~N}+\mathrm{Nz}) * h)$, where $\mathrm{Nz}$ represents the number of added zeros. However, this procedure can adversely affect the accuracy of the resulting estimates and should not be used without careful study of the potential error. For further information on this "zero padding" technique and its effects on analysis parameters, the reader is referred to Bendat and Piersol (1971, pp. 324-236) and Otnes and Enochson (1978, pp. 345-346).

Once the analysis parameters are selected and the data are digitized accordingly, calculation of spectral estimates is a straightforward matter of:

(1) Isolating a time history (or set of q time histories), each of length $\mathrm{N}$.

(2) Examining the data to identify and remove (smooth) any "wild points," "outliers," or "dropouts" that may have been introduced during the data-acquisition process. Although "automatic" procedures for accomplishing this have been described (e.g., Otnes \& Enochson, 1978 , pp. 95-98), this procedure is often done manually, by visual inspection of plots of the data. If enough data exist, it may also be possible to select dropout-free intervals for analysis, discarding any intervals containing noisy or otherwise suspect data.

(3) Removing any "D.C. offset" from the data (insuring that the mean of the data values is zero) by calculating the mean value of the time history and subtracting it from each data point (Bendat \& Piersol, 1971, pp. 288291).

(4) Applying a tapering or "window" function to the time history to attenuate the ends of the sample, thus forcing the data to be periodic in the time window. This process insures compliance with the discrete Fourier transformation requirement that the input record be periodic, with period T. A " $10 \%$ cosine taper" is recommended as a good general-purpose time-domain "window" by Bendat and Piersol and is described here. How. ever, many other different types of time-domain and frequency-domain "windows" exist (Bendat \& Piersol, pp. 323-324).

(5) Performing an N-point FFT with the time history as the "real" FFT input and an array of zeros as the "imaginary" input.

(6) Calculating mean-square power-spectrum estimates from the "real" and "imaginary" FFT results for $\mathrm{K}=1$ to $\mathrm{Ng}$ by:

$$
\begin{aligned}
& \mathrm{G}(\mathrm{K})= \\
& ((\mathrm{REAL}(\mathrm{K}) * * 2)+(\operatorname{IMAG}(\mathrm{K}) * * 2)) *(2 . / \mathrm{N} * * 2)
\end{aligned}
$$

(Bendat and Piersol, p. 327-note that the formula provided by Bendat and Piersol produces power-spectrum density estimates, rather than mean-square powerspectrum estimates).

(7) Adjusting these estimates for the scale factor due to the $10 \%$ cosine taper (Bendat \& Piersol, P. 323):

$$
\mathrm{G}(\mathrm{K})=\mathrm{G}(\mathrm{K}) *(1 . / .875) \text {. }
$$

(8) Converting the mean-square power-spectrum estimates to physical units squared by:

$$
\mathrm{G}(\mathrm{K})=\mathrm{G}(\mathrm{K}) *(\text { SCALE FACTOR } * * 2)
$$

(9) If desired, converting the mean-square powerspectrum estimates to:

(a) RMS amplitude estimates with values of [units] by:

$$
\operatorname{RMS}(\mathrm{K})=\operatorname{SQRT}(\mathrm{G}(\mathrm{K}))
$$

(b) Mean-square power-spectrum density estimates with values of [units squared/Hertz] by:

$$
\operatorname{PSD}(\mathrm{K})=\mathrm{G}(\mathrm{K}) *(1 . / \mathrm{Be})
$$

(c) Mean-square energy-density estimates with values of [units squared/Hertz/sec] by:

$$
\mathrm{ED}(\mathrm{K})=\mathrm{G}(\mathrm{K}) *(1 . / \mathrm{Be}) * \mathrm{~T}
$$

The resulting values represent "raw" spectral estimates in bands located at frequencies $f(K)=(K-1) / T$, where $\mathrm{K}=1$ to $\mathrm{Ng}$, each with a resolution bandwidth of $\mathrm{Be}=1 / \mathrm{T}$.

Smooth spectral estimates can be generated by averaging $b$ neighboring raw (mean-square) spectral estimates (frequency averaging), by averaging estimates from q separate spectra (ensemble or segment averaging), or by combining both techniques. The effect of these smoothing (averaging) procedures on the degrees of freedom, normalized standard error, and resolution bandwidth of spectral estimates are shown in Table 1.

Note that whereas ensemble averaging has no effect on resolution bandwidth (if the original record length is

Table 1

Effect of Averaging Procedure on Spectral Analysis Parameters

\begin{tabular}{clll}
\hline Averaging Procedure & df & NSE & \multicolumn{1}{c}{ RB } \\
\hline None & 2 & 1 & $1 / \mathrm{T}$ \\
Frequency & $2 \mathrm{~b}$ & $1 / \mathrm{b}$ & $\mathrm{b} / \mathrm{T}$ \\
Ensemble & $2 \mathrm{q}$ & $1 / \mathrm{q}$ & $\mathrm{q} / \mathrm{qT}(=1 / \mathrm{T})$ \\
Combined & $2 \mathrm{bq}$ & $1 / \mathrm{bq}$ & $\mathrm{b} / \mathrm{T}$ \\
\hline
\end{tabular}

Note $-N S E=$ normalized standard error $R B=$ resolution band width. 
maintained as $T$ seconds), frequency averaging has the effect of widening the original resolution bandwidth by a factor of $b$, the number of spectral estimates averaged.

Since both averaging techniques are linear operations, the combined averaging procedure may be conducted in either sequence. However, any averaging procedure should be conducted on squared spectral estimates with RMS estimates, (if desired) calculated from the final averaged result.

The procedure used for frequency averaging is (pp. 327-328):

(1) Start with a set of $(\mathrm{Ng})$ spectral estimates $(\mathrm{G}(\mathrm{K})$, $\mathrm{K}=1$ to $\mathrm{Ng}$ ), each with a resolution bandwidth of $\mathrm{Be}=1 / \mathrm{T}$.

(2) Generate a set of $(\mathrm{Ng}) / \mathrm{b}$ averaged spectral estimates by finding the mean of each consecutive (nonoverlapping) set of $b$ raw estimates.

This procedure produces $(\mathrm{Ng}) / \mathrm{b}$ averaged spectral esti. mates of bandwidth $\mathrm{Be}=\mathrm{b} / \mathrm{T}$, with the band midpoints located at frequencies $f(K)=\left(\left((b-1) / 2+\left(b^{*}(K-1)\right)\right) / T\right.$, where $K=1$ to $(\mathrm{Ng}) / \mathrm{b}$.

The procedure used for ensemble averaging is (pp. 328-329):

(1) Start with q sets of $(\mathrm{Ng})$ spectral estimates $(\mathrm{G}(\mathrm{K})$, $\mathrm{K}=1$ to $\mathrm{Ng}$ ), each with a resolution bandwidth of $\mathrm{Be}=1 / \mathrm{T}$.

(2) Generate a set of ( $\mathrm{Ng})$ averaged spectral estimates by finding the mean of the $q$ raw spectral estimates at each frequency $f(K)$.

This procedure produces $(\mathrm{Ng})$ averaged spectral estimates of bandwidth $\mathrm{Be}=1 / \mathrm{T}$, with bands located at frequencies $f(K)=(K-1) / T$, where $K=1$ to $\mathrm{Ng}$.

The ensemble-averaging procedure is most easily implemented by keeping a "running" ensemble average to which successive power spectra can be added as they are calculated. This precludes the need for storage of a potentially large number of individual "raw" spectra.

The mean-square power (or RMS amplitude) in specified frequency bands can be estimated by summing $J$ contiguous mean-square power-spectrum estimates to produce wider frequency bands of resolution bandwidth $B e=J(b / T)$. Summation of all $(\mathrm{Ng})$ mean-square spectrum estimates gives an estimate of the total mean square of the $\mathrm{N}$ input values. The positive square root of the total mean square or of the mean square in smaller frequency bands gives the corresponding RMS amplitude in the frequency bands in question. This analysis is appropriate, of course, for mean-square power-spectrum estimates only, since both power-spectrum-density and energy-density estimates are already normalized to a 1-Hz bandwidth.

The Appendix presents a FORTRAN main program and a set of subroutines to permit the reader to explore the use of spectral analysis using the method described above. These FORTRAN routines are not intended to represent the fastest, most elegant, or most concise procedure that can be used to perform this type of analysis. However, they do work successfully, and they are written in a manner that should permit their imple- mentation in a wide variety of FORTRAN dialects. If speed of processing is a problem for the user, the greatest gains in execution speed probably can be gained through the use of a machine language FFT subroutine that uses fixed-point fractional arithmetic and a sine look-up table. Use of a windowing subroutine that uses stored (rather than computed) cosine values would also improve execution speed. Such routines are often avail able as "system" subroutines on large timesharing computer systems and are often available through computer users' groups or manufacturers. The example input subroutine "GETDAT" generates data that should duplicate the results shown in Figures 3 and 4 below.

Examples of the operation of this technique are presented in Figures 1 through 10, which show the spectra produced by a variety of input time histories. Figure 1 is a sine wave that makes one complete cycle

FIE : SINEI.DAT

STARTING BLOCK NUREER : I

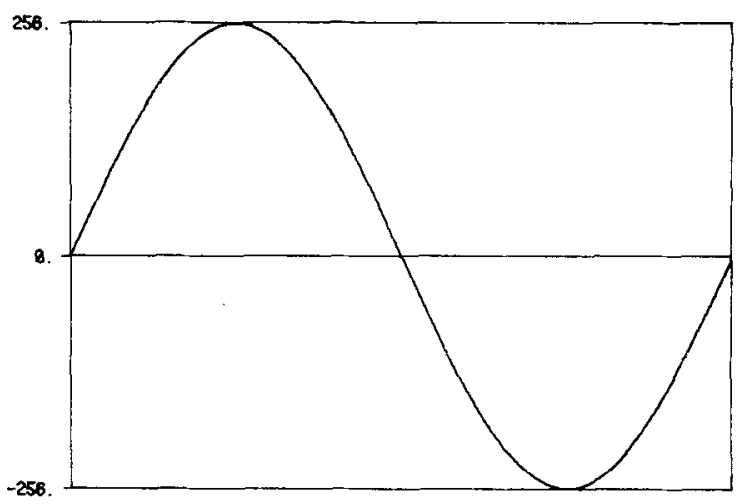

Figure 1. Time history of a one-cycle sine wave.

MEAN SOUARE SPECTRUM OF FILE : SINEI.DAT PEAK VALUE : 32515.5

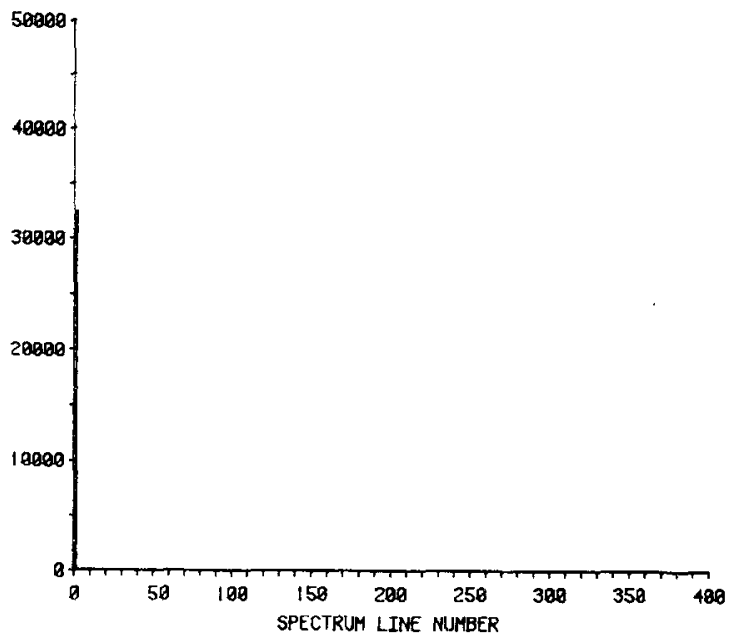

Figure 2. Mean-square spectrum of the sine wave of Figure 1. 
in the input record. Figure 2 is the mean-square spectrum of this signal, a "spike" located at the second line of the spectrum. (The spike is located at the second line of the spectrum, rather than the first, because the first line represents the "D.C.," or constant component, of the input signal.) The spike indicates that all of the variability of the input is associated with a single frequency, in this case, the frequency with period equal to the input record length. Note that the height of the spike is equal to the mean-square value of the input signal. Figure 3 shows a signal that is the sum of three sine waves that make 1,8 , and 32 complete cycles in the input record, respectively. Figure 4 is the mean-

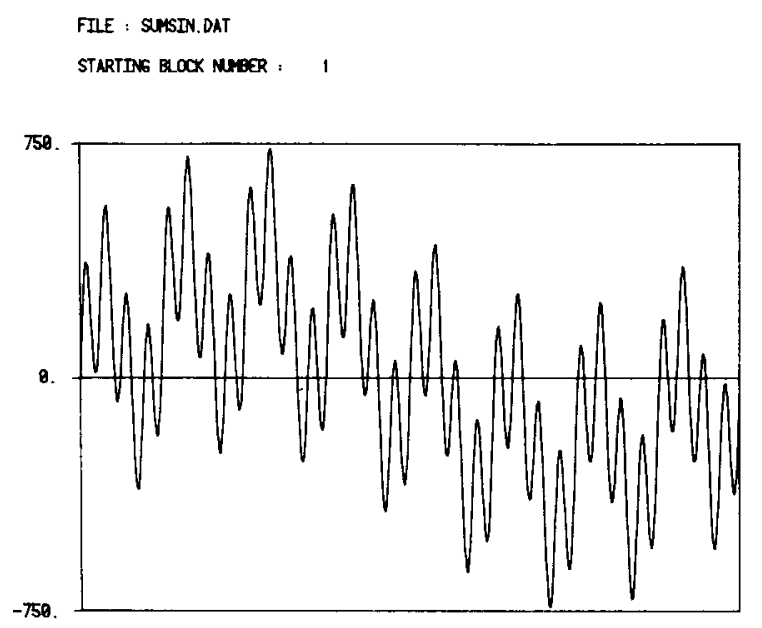

Figure 3. Time history of summed 1-, 8-, and 32-cycle sine waves.

MEAN SOUARE SPECTRUM OF FILE : SUMSIN.DAT PEAK VALUE: 32768.1

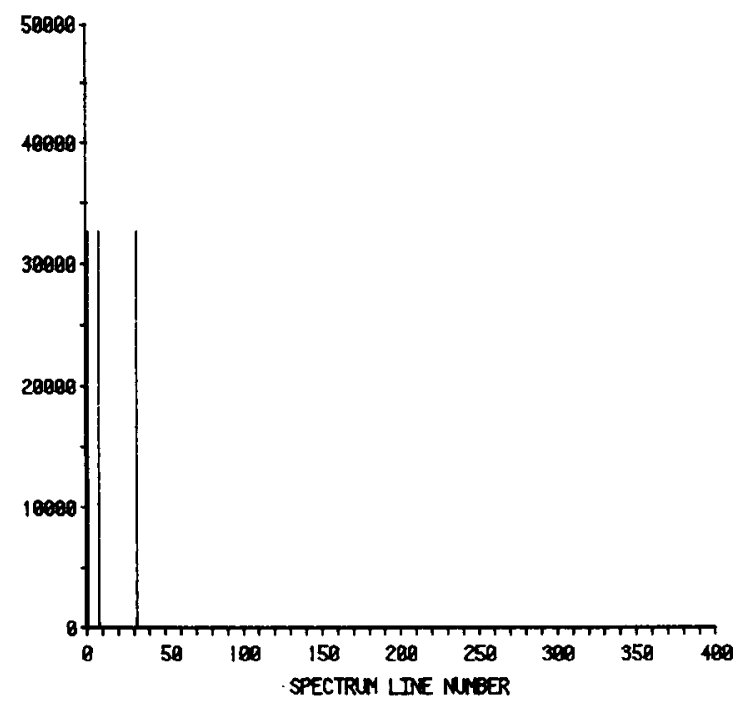

Figure 4. Mean-square spectrum of summed sine waves of Figure 3.

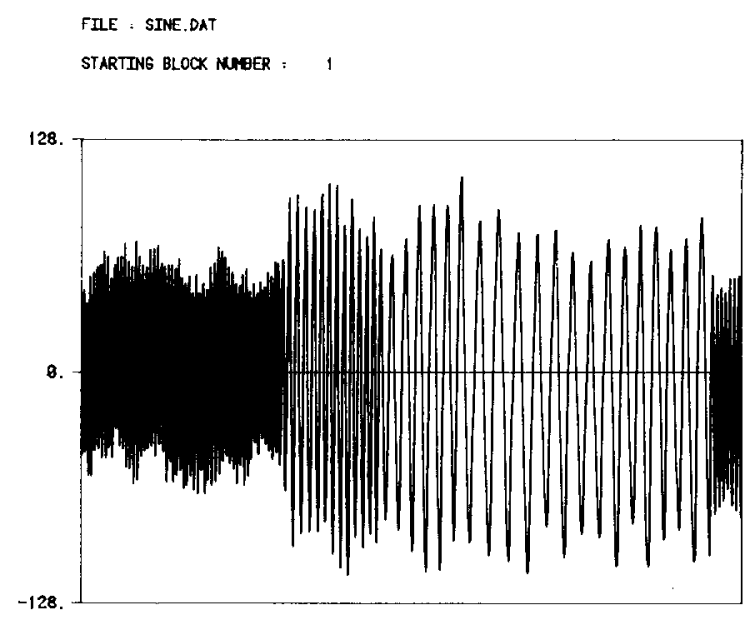

Figure 5. Time history of unknown sinusoidal content.

MEAN SOUARE SPECTRUM OF FILE : SIHE.DAT

PEAK VALUE : 185.183

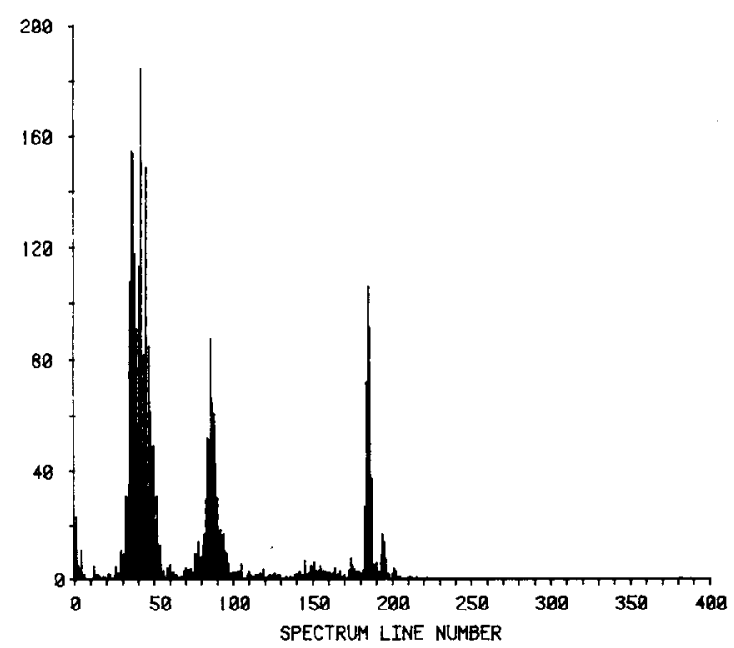

Figure 6. Mean-square spectrum of sinusoidal time history of Figure 5.

square spectrum of this signal, and consists of spikes at the 2 nd, 9 th, and 33 rd positions. (Both of these spectra were calculated using nontapered data. Had the recommended $10 \%$ cosine taper been used, the resulting spectral lines would have appeared wider, resembling the spectrum of Figure 6.)

Figure 5 is a time history that, from visual inspection, appears to be composed of sine waves of three different frequencies. The power spectrum of this signal (Figure 6) bears this out, with three broad spikes evident in the spectrum.

Figures 7 and 9 are time histories of "real" data, in this case, the steering wheel movements made by a beginning driver and an experienced driver, respectively, when they had driven the same automobile on the same section of limited-access highway. The frequency- 
FILE : HL5.DAT

STARTING BLOCX MUEEER :

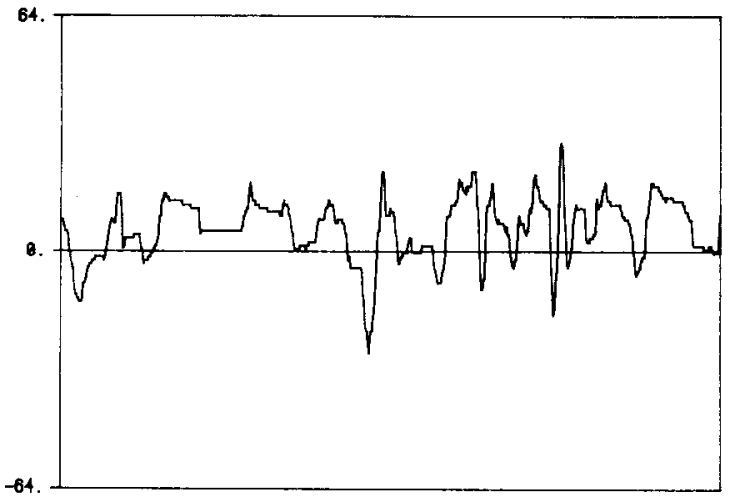

Figure 7. Time history of automobile steering wheel movement of a beginning driver on a limited-access highway.

RMS AMPLITUDE SPECTRUM OF FILE : ML5.DAT

PEAK VALUE : 2.22558

FREQUENCY AVERAGE OVER 3 POINTS

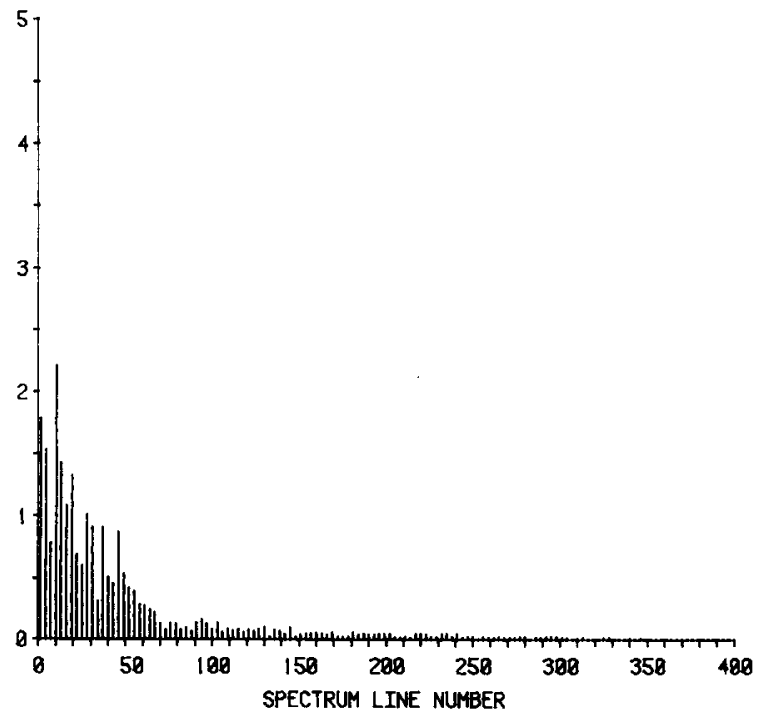

Figure 8. RMS amplitude spectrum of beginning driver's steering.

averaged RMS amplitude spectra of these time histories are shown in Figures 8 and 10, which make it evident that the experienced driver uses a considerably wider range of steering frequencies than does the novice.

Spectral analysis is applicable to a wide variety of physical processes and processes in which human beings act as controlling elements. It is hoped that the brief description of spectral analysis methodology presented here will encourage further exploration of this analysis technique in research and applications of the technique in the study of human behavior.
FILE : SZ5.DAT

STARTING BL OCK MLFBER :

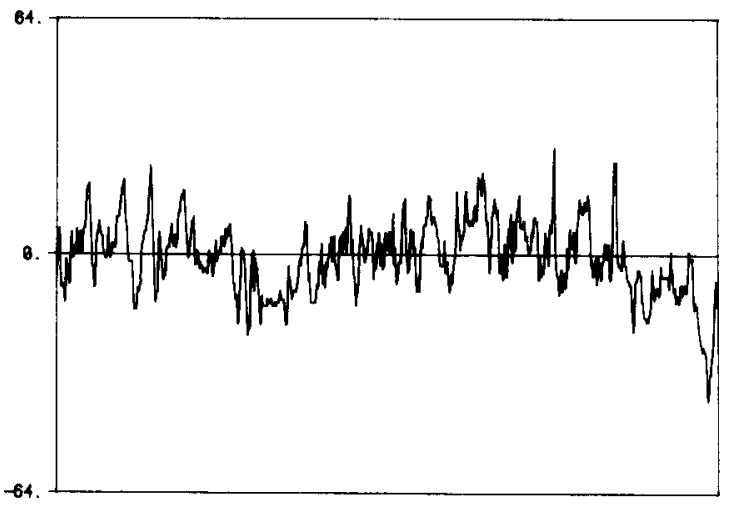

Figure 9. Time history of automobile steering wheel movement of an experienced driver on a limited-access highway.

RMS AMPLITUDE SPECTRUM OF FILE : SZ5.DAT

PEAK VALUE : 2.94152

FREQUENCY AVERAGE OVER 3 POINTS.

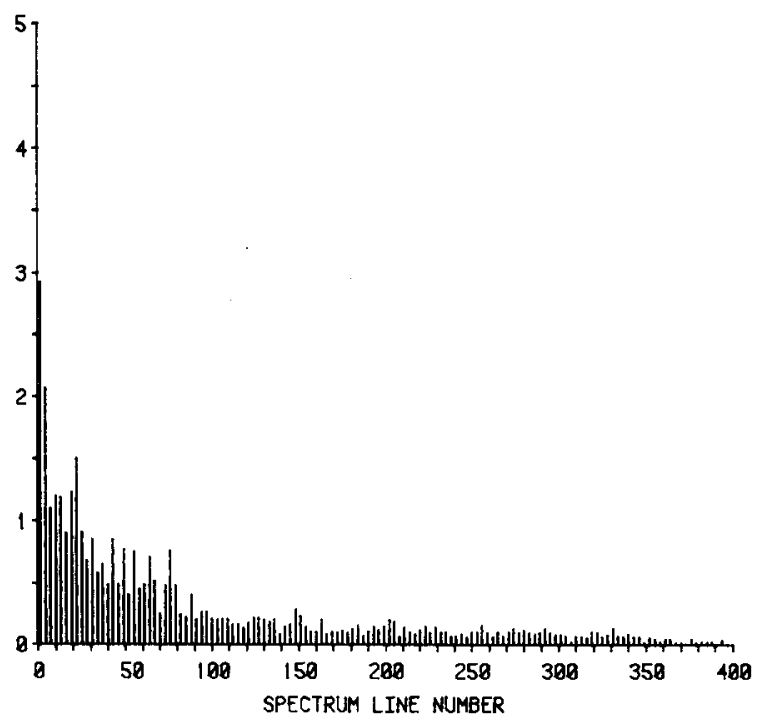

Figure 10. RMS amplitude spectrum of experienced driver's steering.

\section{REFERENCES}

Bendat, J. S., \& Piersol, A. G. Random data: Analysis and measurement procedures. New York: Wiley, 1971.

Eckhouse, R. H., \& Morris, L. R. Minicomputer systems. (2nd ed.). Englewood Cliffs, N.J: Prentice-Hall, 1979.

GenRad, Inc. Operating manual for 2512 spectrum analyzer. Santa Clara, Calif: Author, 1978.

OtNes, R. K., \& ENochson, L. Applied time series analysis. New York: Wiley, 1978.

Sincleton, R. C. An algorithm for computing the mixed radix fast Fourier transform. IEEE Transactions on Audio and Electroacoustics, 1969, AU-17(2), 93-100. 
C. Illustration of the 'Cooley-Tukey' spectral analysis method using both

$C$ ensemble and frequency averaging. Uses subroutines : GETDAT, OFFSET,

C WINDOW, FFT, POWRSP, SCALF, ENSAVE, FRQAVE, and OUTPUT. PROGRAM PSDEMO

REAL REAI.(1024), IMAG(1024), G(400), GAVE(400)

$M=10$

$\mathrm{N}=2 * * \mathrm{M}$

C ' $N G$ ' is the number of unaliased spectral estimates to calculate. $N G=\operatorname{IFIX}(\operatorname{FLOAT}(\mathrm{N}) / 2 . * 0.78125+0.5)$

C Generate and ensemble average 'NQ' power spectra.

NQ $=10$

DO $20 \mathrm{~J}=1, \mathrm{NQ}$

C Get ' $N$ ' points of 'REAL' data to analyze.

CALL GETDAT(REAL, $N$ )

$C$ Zero the ' $N$ ' points of the 'IMAGinary' data array. DO $10 \mathrm{I}=1, \mathrm{~N}$

10

$$
\operatorname{IMAG}(I)=0 \text {. }
$$

C Remove any D.C. offset from the 'REAL' data. CALI, OFFSET(REAL, $N$ )

C Apply a "10\% cosine taper" window to the 'REAL' data. CALL WINDOW(REAL, N)

C Perform the FFT, leaving the results in arrays 'REAL' and 'IMAG'. CALL FFT(REAL, IMAG, M)

C Calculate the ' $N G$ ' power spectrum estimates ' $G$ ' from the FFT results. CALL POWRSP(REAL, IMAG, N, G, NG)

C Scale the spectral estimates to account for the earlier $10 \%$ taper and

$C$ also convert to physical units. PUNIT $=1$. CALI $\operatorname{SCALE}(G, N G, P U N I T)$

C Ensemble average the current "raw" spectrum with the J-1 spectra

$C$ already averaged, leaving the results in array 'GAVE'.

20 CALL ENSAVE(G, NG, GAVE, J-1)

$C$ Frequency average the resulting ensemble averaged spectrum over 'NB'

$C$ points, leaving the resulting $\mathrm{NG} / \mathrm{NB}$ values in array 'GAVE'. $\mathrm{NB}=1$

CALL FRQAVE (GAVE, NG, GAVE, NB)

C Output the resulting NG/NB smoothed spectral estimates. NAVE $=\mathrm{NG} / \mathrm{NB}$

CALI, OUTPUT(GAVE, NAVE) 
Subroutines for use with program 'PSDEMO':

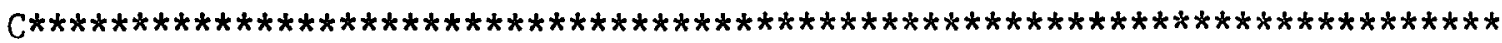

C A routine to fill array 'DATA' with ' $N$ ' data values. Would probably

$C$ read data from a tape or disk file in a real application. SUBROUTINE GETDAT(DATA, N)

REAL DATA(1)

TWOPI $=2 . * 3.1415927$

DELT1 $=$ TWOPI/1024.

DELT8 $=$ TWOPI $/ 128$

$\operatorname{DELT} 32=\mathrm{TWOPI} / 32$.

$\mathrm{Xl}=0$.

$\mathrm{X} 8=0$.

$\mathrm{X} 32=0$.

DO $10 \mathrm{I}=1, \mathrm{~N}$

$\operatorname{DATA}(I)=(\operatorname{SIN}(X 1)+\operatorname{SIN}(X 8)+\operatorname{SIN}(X 32)) * 256$

$\mathrm{X} 1=\mathrm{X} 1+\mathrm{DELT} 1$

$\mathrm{X} 2=\mathrm{X} 2+\mathrm{DELT} 8$

$10 \times 32=\times 32+$ DELT32

RETURN

END

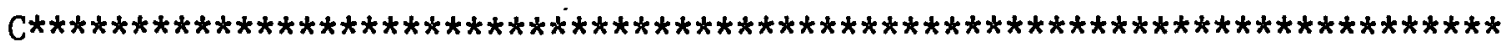

C A routine to remove any D.C. offset (the mean value) from the ' $N$ '

$C$ point long array 'DATA'.

SUBROUTINE OFFSET(DATA, N)

REAL DATA( 1 )

$\mathrm{SUM}=0$.

DO $10 \mathrm{I}=1, \mathrm{~N}$

$10 \quad$ SUM $=$ SUM+DATA $(I)$

FMEAN $=$ SUM $/$ FLOAT $(N)$

DO $20 \mathrm{I}=1, \mathrm{~N}$

$20 \operatorname{DATA}(I)=\operatorname{DATA}(I)-F M E A N$

RETURN

END

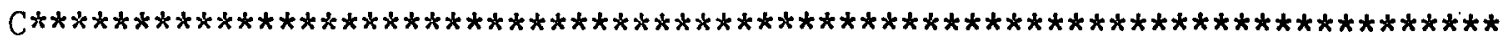

C Routine to apply a "10\% cosine taper" to the ' $N$ ' point long array

C 'DATA'.

SUBROUTINE WINDOW(DATA, N)

REAL DATA( 1 )

$P I=3.1415927$

$\mathrm{N} 10=\mathrm{N} / 10$

FNIO $=$ FLOAT $(\mathrm{NlO})$ 
DO $10 \mathrm{I}=1, \mathrm{~N} 10$

TAPER $=0.5-0.5 * \operatorname{COS}(P I *(F L O A T(I)-0.5) / F N I 0)$

$\operatorname{DATA}(I)=\operatorname{DATA}(I) * \operatorname{TAPER}$

$\mathrm{J}=\mathrm{N}-\mathrm{I}+1$

10

$\operatorname{DATA}(J)=\operatorname{DATA}(J) * \operatorname{TAPER}$

RETISRN

FND

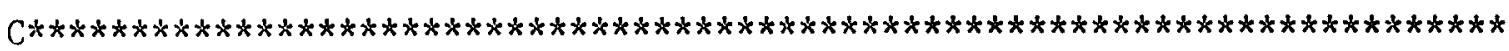

C Routine to calculate and output 'NG' spectral estimates to array 'G'

$C$ with input in ' $N$ ' point long arrays 'REAL' and ' $I M A G$ '.

SUBROUTINE POWRSP(RFAL, IMAG, $N, G, N G$ )

REAL REAL( 1 ), IMAG( 1$), G(1)$

$\operatorname{SFACT}=2 . /(\operatorname{FLOAT}(\mathrm{N}) * \mathrm{FLOAT}(\mathrm{N}))$

DO $10 \mathrm{I}=1, \mathrm{NG}$

10

$G(I)=(\operatorname{REAL}(I) * * 2+\operatorname{IMAG}(I) * * 2) * \operatorname{SFACT}$

RETIJRN

END

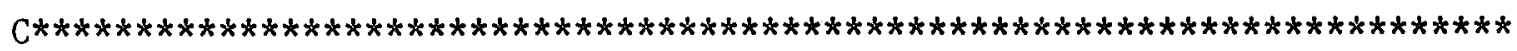

C Routine to correct ' $N G^{\prime}$ point long array ' $G$ ' for scaling error intro-

$C$ duced by earlier cosine tapering and convert output to physical units

$C$ using scale factor 'PUNIT'.

SUBROUTINE SCALF( $G, N G, P U N I T)$

REAL G(1)

$\mathrm{SFACT}=1 . / .875$

SFACT $=$ SFACT* $($ PUNIT**2)

DO in $I=1, N G$

10

$G(I)=G(I) *$ SFACT

RETIJRN

END)

$C * * * * * * * * * * * * * * * * * * * * * * * * * * * * * * * * * * * * * * * * * * * * * * * * * * * * * * * * * * * * * * * * * * * * * * *$

$C$ Routine to frequency average the ' $N G$ ' points of array 'G' over ' $N B$ '

$C$ points, with the $N G / N B$ resulting points in array 'GFAVF'.

SUBROUTINE FRQAVE( $G, N G$, GFAVE, NB)

REAL $G(1), \operatorname{GFAVE}(1)$

$\mathrm{FNB}=\operatorname{FLOAT}(\mathrm{NB})$

$I B E G=1$

$I E N D=N B$

$\mathrm{NAVE}=\mathrm{NG} / \mathrm{NB}$

DO $20 \mathrm{~J}=1$, NAVE

$T E M P=0$. 
DO $10 \mathrm{~K}=$ IBEG, IEND

TEMP $=$ TFMP $+G(K)$

$\operatorname{GFAVE}(J)=\operatorname{TFMP} / \mathrm{FNB}$

20

$\mathrm{IBEG}=\mathrm{IBEG}+\mathrm{NB}$

IFND $=$ IEND + NB

RETURN

END

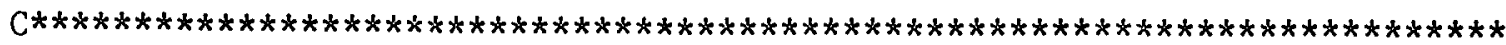

C Routine to perform a 'running' ensemble average of the 'NG' points of

$C$ the array ' $G$ ' with the ' $N Q$ ' arrays already averaged in array 'GEAVE'.

$C$ Results are put in array 'GEAVE'.

SUBROUTINE ENSAVE(G,NG, GEAVE, NQ)

REAL G(1), GEAVE (1)

10

$\mathrm{FNQ}=\operatorname{FLOAT}(\mathrm{NQ})$

$\mathrm{FNQ1}=\mathrm{FNQ}+1$.

DO $10 \mathrm{~K}=1$, NG

$\operatorname{GEAVE}(K)=((\operatorname{GEAVE}(K) * \mathrm{FNQ})+\mathrm{G}(\mathrm{K})) / \mathrm{FNQ} \mathbf{l}$

RETURN

END

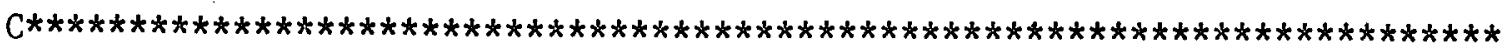

C Routine to output the ' $N$ ' values of array 'DATA'. Would probably

$C$ output to a plotter or other graphic device in a real application. SUBROUTINE OUTPUT(DATA, N)

REAL DATA( 1 )

$\operatorname{WRITE}(7,1)(\operatorname{DATA}(K), K=1, N)$

$1 \quad$ FORMAT $(1 \mathrm{H}, 8 \mathrm{G} 10.3)$

RETURN

END

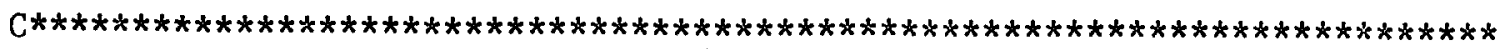

C Routine to perform a $2 * \star M$ point FFT on data in arrays 'REAL' and

$C$ ' $M$ MAF' with results returned in the input arrays. Adapted from FFT

C shown in Eckhouse and Morris (1979), p. 289.

SUBROUTINE FFT(REAL, IMAG,M)

REAL REAL (1), $\operatorname{IMAG}(1)$

$N=2 * * M$

$\mathrm{PI}=3.1415927$

$\mathrm{NV} 2=\mathrm{N} / 2$

$\mathrm{NM} 1=\mathrm{N}-1$

$\mathrm{J}=1$ 


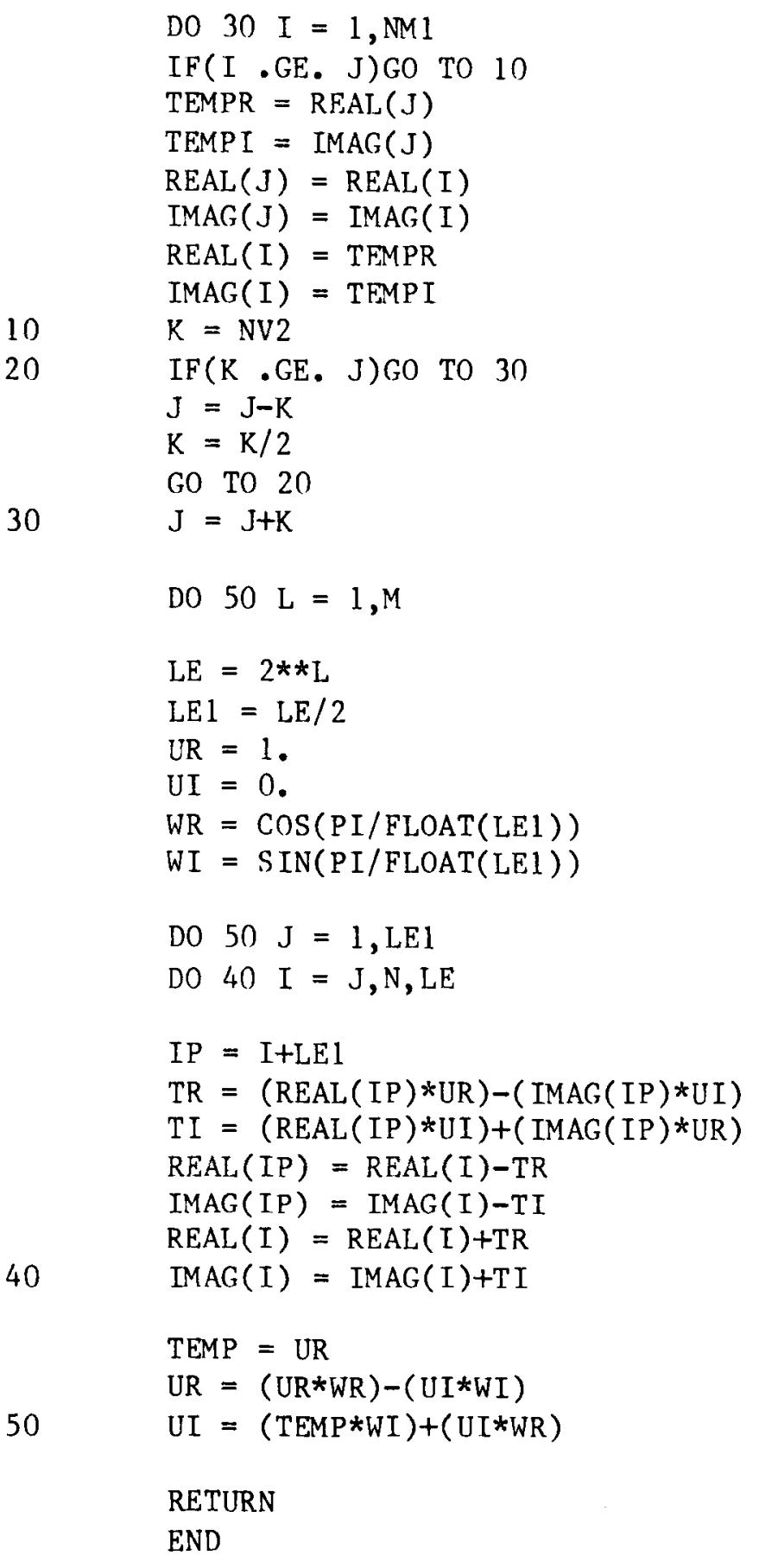

(Manuscript received December 7, 1982;

revision accepted for publication March 29, 1983.) 